\title{
Evaluation of Left Ventricle Systolic and Diastolic Functions by Tissue Doppler Echocardiography in Children with Down Syndrome
}

\author{
Saeed Abtahi,, ${ }^{1}$ Pouya Nezafati, ${ }^{2}$ Hamid Amoozgar, ${ }^{3}$ Maryam Rafie-Torghabe, ${ }^{1}$ and Mohammad Hassan \\ Nezafati ${ }^{4, *}$ \\ ${ }^{1}$ Department of Pediatric Cardiology, Mashhad Branch, Islamic Azad University, Mashhad, IR Iran \\ ${ }^{2}$ Student Research Committee, Mashhad University of Medical Sciences, Mashhad, IR Iran \\ ${ }^{3}$ Neonatology and Cardiovascular Research Center, Nemazi Hospital, Shiraz University of Medical Sciences, Shiraz, IR Iran \\ ${ }^{4}$ Department of Cardiac Surgery, Ghaem Hospital, Mashhad University of Medical Sciences, Mashhad, IR Iran \\ "Corresponding author: Mohammad Hassan Nezafati, Department of Cardiac Surgery, Ghaem Hospital, Mashhad University of Medical Sciences, Mashhad, IR Iran. Tel: \\ +98-9151578421, Fax: +98-5137635535, E-mail: mhnezafati@yahoo.com
}

Received 2016 February 18; Revised 2016 July 02; Accepted 2016 August 18.

\begin{abstract}
Background: Tissue Doppler imaging evaluates the ventricular function in both systolic and diastolic assessments.

Objectives: This study aimed to determine the level of cardiac function in children with Down syndrome without structural cardiac lesions using conventional and tissue Doppler echocardiography.

Methods: From September 2013 to August 2014 in Mashhad, Iran, a group of 36 children with Down syndrome aged between 4 months and 19 years without anatomic heart disease had their ventricular function assessed by both 2D echocardiography and tissue Doppler imaging. The following were measured: velocity of systolic waves $(\mathrm{S})$, traditional Doppler imaging of early diastolic waves (E), traditional Doppler imaging of late diastolic waves (A), tissue Doppler imaging early diastolic waves (E'), and tissue Doppler imaging late diastolic waves (A') at the mitral and tricuspid valve levels. Other data, such as fractional shortening, heart rate, and ejection fraction, were also measured.

Results: At the time of the examination, the mean age of the participants was $6.4 \pm 5.5$ years. An association was found between children's age and the tricuspid A-wave. The A-wave velocity of the tricuspid annulus increased when the body surface area decreased. In addition, compared with the normal subjects, the large age group presented with considerable differences in wave speed, including $\mathrm{E}, \mathrm{A}$, and E/E', at the mitral and tricuspid annulus levels.

Conclusions: Despite the Down syndrome children having an apparently normally structured heart, tissue Doppler imaging reveals different findings than those of normal children. The findings of this modality can be used to explain the reason behind the limited physical functioning of children with Down syndrome and may be considered as predictive factors for future cardiac events in these children.
\end{abstract}

Keywords: Ventricular Function, Tissue Doppler Imaging, Down Syndrome

\section{Background}

Down syndrome is the most common chromosomal defect among children worldwide. It is the result of an aberration of chromosome 21 and may cause congenital heart disease, diabetes mellitus, and hypothyroidism, among other issues (1). As a common association, congenital heart disease occurs in almost $40 \%-50 \%$ of Down syndrome patients, $30 \%$ of whom have several cardiac defects (2).

Diagnostic tests are necessary to ensure an accurate diagnosis. A comprehensive physical examination is the main means of diagnosis (3). Electrocardiography, Holter monitoring, chest imaging, echocardiography, and magnetic resonance imaging (MRI) are also used to diagnose several cardiac defects (4).

Echocardiography is the conventional non-invasive procedure used to monitor the function and structure of the heart. Tissue Doppler imaging is a new type of echocardiography that has the advantage of permitting the ventricles to be studied, both in systole and diastole. Tissue Doppler imaging is not only used in evaluating ventricular systolic and diastolic functions but is also beneficial in detecting uncoordinated ventricular movements (5). It can be performed in various formats: M mode, $2 \mathrm{D}$ mode, and spectral pulsed wave (6). Differentiating among the various phases of the cardiac cycle is now possible using an echocardiography tissue Doppler (7). This imaging method enhances the use of echocardiography by calculating systolic and diastolic intervals in a frequent, safe, costeffective, and geometrically independent technique (8-12). It is especially important for analyzing the right ventricle in general and the left ventricle when it has a peculiar mor- 
phology or regional wall-motion abnormalities. However, its use in children with congenital and acquired heart diseases continues to expand (13).

Whereas structurally abnormal hearts have been greatly examined in Down syndrome patients, studies on the cardiac function of normally structured hearts in Down syndrome subjects are scarce. As Down syndrome patients have begun to expect a longer life than before in recent years, a thorough investigation is needed to examine their heart functions to find an explanation for the exercise intolerance, decrease in work capacity, and high rate of morbidity and mortality experienced in adolescence.

\section{Objectives}

This study aimed to evaluate the ventricular systolic and diastolic functions among Down syndrome patients with no anatomical heart defects

\section{Methods}

This work was a descriptive study undertaken from September 2013 to August 2014 in Mashhad, Iran. All patients were chosen because of their availability during their visit to a single pediatric cardiology clinic. Thirty-six patients under 18 years of age with no anatomical heart defects were selected. We excluded participants with Down syndrome associated with any heart or systemic diseases, pulmonary artery pressure greater than $25 \mathrm{mmHg}$, a history of cardiac surgery, and a history of hormone therapy.

Thirty-six children were selected to determine their ventricular systolic and diastolic functions using $2 \mathrm{D}$ echocardiography and tissue Doppler echocardiography. To ensure their complete health status and lack of systemic disorders, a pediatric cardiologist examined all patients. Further, patients underwent tissue and Doppler echocardiography to evaluate their myocardial wall motion rate parallel to the mitral and tricuspid valves. Afterwards, data were recorded and statistically analyzed for each child. Ejection fraction and heart rate were recorded using echocardiography. In addition, body surface area, which is the 2D measure of the outer layer of the body, was measured in $\mathrm{m}^{2}$.

We used a GE Vivid 3 ultrasound system with a probe of 4 - $6 \mathrm{MHz}$ frequency. Tissue Doppler imaging waveforms were recorded and analyzed. Early diastolic waves (E), late diastolic waves (A), systolic waves (S), tissue Doppler imaging early diastolic waves (E'), and tissue Doppler imaging late diastolic waves (A') were used for the analysis of the two regions of the mitral valve and tricuspid valve.
M-mode and 2D echocardiography were used to measure the internal dimensions, ejection fraction, and fractional shortening of the left ventricle. These measurements were conducted on the basis of recommendations from the American society of echocardiography (14). Teichholz formulas were used to calculate the ejection fraction by measuring the inner diameter short axis of the left ventricle using M-mode (15).

\subsection{Tissue Doppler Echocardiography}

Low gain and low filter settings were used to prevent high-frequency signals. The sample volume gate was 2 - 3 $\mathrm{mm}$ long, and the sweep speed was $100 \mathrm{~mm} / \mathrm{s}$. The sample volume was located in the myocardium at an equal distance from the epicardium and the endocardium. The myocardial velocity curves of the mitral septum valve annulus, the lateral mitral valve annulus, and the lateral tricuspid valve annulus were recorded using the apical fourchamber planes using the tissue Doppler imaging technique; cycle events were measured using electrocardiogram. The initiation of the QRS complex was considered the reference point. Right or left ventricular functions were shown by systolic waves. Both the E'/A' and E/E' ratios of the mitral and tricuspid valve annuli were considered the diastolic function of the left and right ventricles, respectively. At least 10 cardiac courses were recorded, and the images were saved and preserved electronically. Tissue Doppler imaging determined the children's cardiac volume (16). All parents signed an informed consent form that was certified by the ethics committee before enrolling in the study.

\subsection{Statistical Analysis}

Data were expressed as means (SD) for parameters with a normal distribution. Quantitative data were analyzed using the single-sample Kolmogorov-Simonov test. Sample t-tests were used for normal results; otherwise, nonparametric testing was applied. Non-parametric quantitative data were analyzed using the Mann-Whitney test. A two-sided P value of 0.05 was considered statistically significant. Variances were applied to assess the effects of independent variants on wave speed. Bivariate correlations between different parameters and velocity movement waves at the mitral and tricuspid valves were performed using Pearson's rank correlation. Stepwise multiple linear regression analysis was used to determine which of the conventional risk factors influence cardiac waves. The software used in this study was SPSS for windows ${ }^{\mathrm{TM}}$ version 11.5 package (SPSS Inc., Chicago, IL, USA). 


\section{Results}

A total of 36 subjects were included in this study. The baseline characteristics of the total population are shown in Table 1. At the time of the examination, the mean age of the participants was $6.4 \pm 5.5$ years, and the majority (55\%) was under 5 years old. Physical examination revealed a variety of body surface area distributions: 9 subjects between 0.0 and $0.5 \mathrm{~m}^{2}$ (25.0\%), 22 subjects between 0.5 and 1 $\mathrm{m}^{2}$ (61.1\%) and 5 subjects between 1 and $1.5 \mathrm{~m}^{2}$ (13.9\%). The mean heart rate was $103.7 \pm 16.2$, and the mean ejection fraction and fractional shortening were $69.8 \pm 4.8 \%$ and $38.9 \pm 3.9 \%$, respectively.

Table 1. Patients' Demographic Data

\begin{tabular}{lccc}
\hline Parameter & Data & Maximum & Minimum \\
\hline Age, $\mathbf{y}$ & $6.4 \pm 5.5$ & 18 years & 4 months \\
\hline Sex & 17 female, 19 male & - & - \\
\hline Weight, Kg & $18.16 \pm 10.9$ & 47 & 5.6 \\
\hline Height, cm & $98.67 \pm 23.68$ & 142 & 61 \\
\hline BSA, $\mathbf{m}^{2}$ & $0.69 \pm 0.28$ & 1.33 & 0.33 \\
$\begin{array}{l}\text { Heart rate (pulse per } \\
\text { minute) }\end{array}$ & $103.67 \pm 16.15$ & 130 & 72 \\
\hline
\end{tabular}

\subsection{Analysis of Covariance}

According to the univariate analysis, the results showed that tricuspid annulus $\mathrm{E}$ wave $(\beta=1.94, \mathrm{P}=0.01$, $\mathrm{CI}=0.95$ ) was independently associated with age values. In addition, tricuspid annulus $A$ wave was independently associated with body surface area values $(\beta=3.8, \mathrm{P}=0.03$, $\mathrm{CI}=0.95)$. All other waves that originated from each of the two sample sites, including the mitral annulus and tricuspid annulus, measured by Doppler tissue imaging were not statistically associated with age, heart rate, gender, or body surface area $(\mathrm{P}>0.05)$. Moreover, ejection fraction had no significant association with gender, age, or body surface area.

\subsection{Correlations}

Pearson's correlation test was used to evaluate the possible correlation between speed of cardiac waves with body surface area and patients' age. Note that an inverse correlation between body surface area and tricuspid annulus A wave was observed $(r=-0.35, P=0.002)$.

Based on the book Moss and Adam's heart disease in infants, children, and adolescents ( $7^{\text {th }}$ edition) (17), wave speeds at the mitral annulus of the Down syndrome patients and normal patients of this study are shown In Table 2. The movement of wave speed at the mitral annulus of Down syndrome patients and normal children between
10 and 18 years old was considerably different. Moreover, among individuals between 4 months and 9 years of age, a notable difference was found between the two groups in the majority of mitral valve waves. However, mitral annulus E' wave, A' wave motion velocity, and the E/A velocity wave ratio of Down syndrome children and normal individuals did not differ as much. At the level of the tricuspid valve, wave speeds, including the velocity ratios of E', A', and $E / A$ waves, were not relatively different among different age groups. However, other tricuspid valve wave speeds showed a notable difference between the two groups.

\section{Discussion}

The live birth prevalence of Down syndrome is about $0.1 \%$, and one of the most common problems in patients suffering from Down syndrome is congenital cardiac defects (18). These patients may present with or without any anatomical or functional defects that can be visualized in imaging tests such as echocardiography. Despite advances in the diagnosis and treatment of Down syndrome patients with structural heart disease $(19,20)$, studies on the group of Down syndrome with apparently normally structured heart are needed. Therefore, this study investigated the cardiac systolic and diastolic functions of 36 patients with Down syndrome who had no history of congenital heart disease using the tissue echocardiography technique.

Our study revealed a relatively high heart rate of Down syndrome patients compared with that of normal subjects in other reports. Our study agreed with the results of these reports, which indicated a significantly higher heart rate in Down syndrome subjects than in normal children (2123). This finding is considered to be due to the autonomic cardiac dysfunction occurring at the central brain stem site as a result of a genetic disorder (24). In another investigation conducted among 22 Down syndrome patients who had no congenital heart defects, the fractional shortening was $40.2 \% \pm 6.1(\mathrm{P}<0.001$, in comparison with normal subjects), whereas in our study the fractional shortening was 38.9\%, which is comparable with their finding (25). Their study showed a high left ventricular ejection fraction (69.8\%) compared with those from other reports of normal subjects (25). They believed that this higher ejection fraction is due to the reduced afterload and not to the intrinsic abnormalities of the myocardium. Al-Biltagi et al. reported a relatively similar ejection fraction in their Down syndrome subjects (68.1\%), and it was significantly higher than that of their normal group subjects (21).

According to 2D echocardiography and tissue Doppler, the E/A and E'/A' ratios at the mitral valve were $1.61 \pm 0.37$ and $1.92 \pm 0.78$, respectively, which reflect a decreased left 
Abtahi S et al.

Table 2. Comparison of Cardiac Wall Movement at the Mitral Valve Between Down Syndrome Patients and Normal Subjects ${ }^{\mathrm{a}}$

\begin{tabular}{|c|c|c|c|}
\hline Age, $y$ & Sort of Wave & Patients & Normal Subjects \\
\hline \multirow{5}{*}{ Under 1} & E' & $0.1 \pm 0.02$ & $0.1 \pm 0.03$ \\
\hline & $\mathrm{A}^{\prime}$ & $0.06 \pm 0.01$ & $0.06 \pm 0.02$ \\
\hline & A & $0.72 \pm 0.14$ & $0.65 \pm 0.13$ \\
\hline & $\mathrm{E} / \mathrm{A}$ & $1.5 \pm 0.25$ & $1.2 \pm 0.3$ \\
\hline & $\mathrm{E} / \mathrm{E}^{\prime}$ & $11.02 \pm 3.17$ & $8.80 \pm 2.70$ \\
\hline \multirow{6}{*}{01 - 05} & $\mathrm{E}^{\prime}$ & $0.12 \pm 0.02$ & $0.15 \pm 0.03$ \\
\hline & $A^{\prime}$ & $0.07 \pm 0.03$ & $0.07 \pm 0.02$ \\
\hline & $\mathrm{E}$ & $1.2 \pm 0.16$ & $0.9 \pm 0.2$ \\
\hline & A & $0.80 \pm 0.22$ & $0.61 \pm 0.12$ \\
\hline & $\mathrm{E} / \mathrm{A}$ & $1.58 \pm 0.33$ & $1.60 \pm 0.50$ \\
\hline & $\mathrm{E} / \mathrm{E}^{\prime}$ & $10.36 \pm 2.29$ & $6.5 \pm 2.00$ \\
\hline \multirow{5}{*}{$06-09$} & $\mathrm{E}^{\prime}$ & $0.14 \pm 0.02$ & $0.17 \pm 0.04$ \\
\hline & $\mathrm{E}$ & $1.17 \pm 0.09$ & $0.94 \pm 0.15$ \\
\hline & A & $0.74 \pm 0.16$ & $0.61 \pm 0.13$ \\
\hline & $\mathrm{E} / \mathrm{A}$ & $1.64 \pm 0.35$ & $2.00 \pm 0.50$ \\
\hline & $\mathrm{E} / \mathrm{E}^{\prime}$ & $8.71 \pm 1.80$ & $5.80 \pm 1.90$ \\
\hline \multirow{6}{*}{$10-13$} & E' & $0.13 \pm 0.05$ & $0.20 \pm 0.03$ \\
\hline & $A^{\prime}$ & $0.10 \pm 0.03$ & $0.06 \pm 0.02$ \\
\hline & $E$ & $1.07 \pm 0.17$ & $0.95 \pm 0.16$ \\
\hline & A & $0.69 \pm 0.33$ & $0.5 \pm 0.14$ \\
\hline & $\mathrm{E} / \mathrm{A}$ & $1.78 \pm 0.68$ & $2.00 \pm 0.60$ \\
\hline & $\mathrm{E} / \mathrm{E}^{\prime}$ & $9.13 \pm 4.71$ & $4.90 \pm 1.3$ \\
\hline \multirow{5}{*}{$14-18$} & $\mathrm{E}^{\prime}$ & $0.13 \pm 0.02$ & $0.21 \pm 0.04$ \\
\hline & $\mathrm{A}^{\prime}$ & $0.05 \pm 0.01$ & $0.07 \pm 0.02$ \\
\hline & $\mathrm{E}$ & $1.11 \pm 0.21$ & $0.90 \pm 0.18$ \\
\hline & $\mathrm{E} / \mathrm{A}$ & $1.72 \pm 0.39$ & $2.1 \pm 0.70$ \\
\hline & $\mathrm{E} / \mathrm{E}^{\prime}$ & $8.79 \pm 2.15$ & $4.7 \pm 1.3$ \\
\hline
\end{tabular}

${ }^{\mathrm{a}}$ Values are expressed as mean $\pm \mathrm{SD}$.

ventricular diastolic function compared with that of normal children in other reports $(21,22)$. In other studies, these ratios were reported to be lower in their Down syndrome subjects than in their control group. This finding is considered to be due to the impaired cardiac muscle relaxation. Although similar to other studies, this low ratio in Down syndrome children was not associated with a clinical manifestation.

In the echocardiographic findings for the myocardial movement of the tricuspid annulus, the ratio of E/A waves was 1.35 and the speed ratio of E'/A' waves 1.57. In a similar study conducted by Al-Biltagi, these rates were reported to be 1.57 and 1.04 , respectively (21). Both these ratios were lower than those of normal subjects in other reports that found a similar difference $(21,22)$. This weakened rightsided diastolic performance may be due to defective cardiac autonomic performance, cardiac hypertrophy by in- hibited calcineurin signaling, or cardiac muscle fiber dysfunction (13, 26-30).

Roberson et al. reported a normal velocity of wave motion in the area of the tricuspid valve in children without any cardiac disease (12). In our study, the movement velocity of S, E', and A' waves varied at 0.07- $0.19(\mathrm{~m} / \mathrm{s}), 0.06-0.32$ $(\mathrm{m} / \mathrm{s})$, and $0.05-0.23(\mathrm{~m} / \mathrm{s})$ respectively. Conversely, these movement velocities varied at $0.01-0.31(\mathrm{~m} / \mathrm{s})$ for $S$ waves, $0.02-0.32(\mathrm{~m} / \mathrm{s})$ for E' waves, and $0.01-0.29(\mathrm{~m} / \mathrm{s})$ for $A^{\prime}$ waves in Roberson's study. These results suggest that the ranges of movement velocity distribution of waves originating from the tricuspid valve are comparatively shorter in Down syndrome patients than in the normal population (12).

Pulmonary hypertension is considered one of the most common complications in children with Down syndrome even without the presence of any structural heart defects 
$(21,31)$. Frequent pulmonary infections, chronic constriction of the upper airway, abnormal structure, and pulmonary vessel growth are the major causes of pulmonary arterial hypertension that may develop in Down syndrome patients (32). However, patients with high pulmonary artery pressure were excluded in our study, and thus it could not have had a confounding effect on our interpretations.

One of the limitations of this study is our small sample size. The absence of a control group from our patients to compare our results with is another important limitation of this study. Based on the results, further investigations on the ventricular systolic and diastolic functions of larger populations of patients with Down syndrome would be useful.

As patients with Down syndrome may have functional cardiac defects without any considerable structural cardiac abnormalities, the standard type of tissue echocardiography imaging may be a safe and useful method to evaluate both regional and global systolic or diastolic ventricular function. This method can also be a prognostic factor to uncover the possible cardiac events resulting in shorter life expectancy in the future. These findings may explain why children with Down syndrome have limited physical performance abilities and are susceptible to many cardiovascular defects. Further investigations are suggested to examine the predictive value of different waves from the tissue Doppler imaging in cardiac events occurring in the long term for Down syndrome children with structurally normal hearts.

\section{Acknowledgments}

The authors would like to thank all the patients and their guardians for their cooperation and permission to publish this article.

\section{References}

1. Hamada T, Gejyo F, Koshino Y, Murata T, Omori M, Nishio M, et al. Echocardiographic evaluation of cardiac valvular abnormalities in adults with Down's syndrome. Tohoku J Exp Med. 1998;185(1):31-5. [PubMed: 9710943].

2. Barlow GM, Chen XN, Shi ZY, Lyons GE, Kurnit DM, Celle L, et al. Down syndrome congenital heart disease: a narrowed region and a candidate gene. Genet Med. 2001;3(2):91-101. [PubMed: 11280955].

3. Moller J, Hoffman H. Pediatric Cardiovascular Medicine.1 ed. Philadelphia: Chuerchil Livingstone; 2002.

4. Bailey JJ, Berson AS, Garson A, Horan LG, Macfarlane PW, Mortara DW, et al. Recommendations for standardization and specifications in automated electrocardiography: bandwidth and digital signal processing. A report for health professionals by an ad hoc writing group of the Committee on Electrocardiography and Cardiac Electrophysiology of the Council on Clinical Cardiology, American Heart Association. Circulation. 1990;81(2):730-9. [PubMed: 2297875].
5. Lewis AB, Pilkington R, Takahashi M, Siegel SE. Echocardiographic assessment of anthracycline cardiotoxicity in children. Med Pediatr Oncol. 1978;5(1):167-75. [PubMed: 745585].

6. Bruch C, Gradaus R, Gunia S. Doppler tissue analysis of mitral annular velocities: evidence for systolic abnormalities in patients with diastolic heart failure. J Am Soc Echocardiogr. 2003;16(10):1031-6.

7. Zamorano J, Wallbridge DR, Ge J, Drozd J, Nesser J, Erbel R. Noninvasive assessment of cardiac physiology by tissue Doppler echocardiography. A comparison with invasive haemodynamics. Eur Heart J. 1997;18(2):330-9. [PubMed: 9043850].

8. Harada K, Tamura M, Toyono M, Oyama K, Takada G. Assessment of global left ventricular function by tissue Doppler imaging. Am J Cardiol. 2001;88(8):927-32. [PubMed: 11676968].

9. Pai R. G. , Gill K. S. . Amplitudes, durations and timings of apically directed left ventricular myocardial velocities: I, their normal pattern and coupling to ventricular filling and ejection. JAm Soc Echocardiogr. 1998;11:105-11.

10. Cui W, Roberson DA. Left ventricular Tei index in children: comparison of tissue Doppler imaging, pulsed wave Doppler, and M-mode echocardiography normal values. $J$ Am Soc Echocardiogr. 2006;19(12):1438-45. doi: 10.1016/j.echo.2006.06.006. [PubMed: 17138026].

11. Gaibazzi N, Petrucci N, Ziacchi V. Left ventricle myocardial performance index derived either by conventional method or mitral annulus tissue-Doppler: a comparison study in healthy subjects and subjects with heart failure. J Am Soc Echocardiogr. 2005;18(12):1270-6. doi: 10.1016/j.echo.2005.06.006. [PubMed: 16376754].

12. Roberson DA, Cui W. Right ventricular Tei index in children: effect of method, age, body surface area, and heart rate. J Am Soc Echocardiogr. 2007;20(6):764-70. doi: 10.1016/j.echo.2006.11.002. [PubMed: 17543749].

13. Markham JAMLW, Michelfelder EC, Border WL. Abnormalities of diastolic function precede dilated cardiomyopathy associated with Duchenne muscular dystrophy. Soc Echocardiogr. 2006;19(7):865-71.

14. Picard MH, Adams D, Bierig SM, Dent JM, Douglas PS, Gillam LD, et al. American Society of Echocardiography recommendations for quality echocardiography laboratory operations. J Am Soc Echocardiogr. 2011;24(1):1-10. doi: 10.1016/j.echo.2010.11.006. [PubMed: 21172594].

15. Cevik Y, Degertekin M, Basaran Y, Turan F, Pektas O. A new echocardiographic formula to calculate ejection fraction by using systolic excursion of mitral annulus. Angiology. 1995;46(2):157-63. [PubMed: 7702201].

16. Ng AC, Thomas L, Leung DY. Tissue Doppler echocardiography. Minerva Cardioangiol. 2010;58(3):357-78. [PubMed: 20485241].

17. Kimball TR, Michelfelder EC. Echocardiography. 7 ed. Philadephia: Lippincott, Williams, and Wilkins; 2008. pp. 156-7.

18. Rosenquist GC, Sweeney LJ, McAllister HA. Relationships of the tricuspid valve to the membranous ventricular septum in Down's syndrome without endocardial cushion defect: Study of 28 specimens, 14 with a ventricular septal defect. Am Heart J. 1975;90(4):458-62.

19. Nezafati MH, Soltani G, Mottaghi H, Horri M, Nezafati P. Videoassisted thoracoscopic patent ductus arteriosus closure in 2,000 patients. Asian Cardiovasc Thorac Ann. 2011;19(6):393-8. doi: 10.1177/0218492311424782. [PubMed: 22160407].

20. Nezafati P, Nezafati MH, Hoseinikhah H. Unruptured Aneurysm of Sinus of Valsalva Coexisting with the Large Ventricular Septal Defect and Severe Aortic Regurgitation in a Young Man. Case Rep Med. 2015;2015:396098.

21. Al-Biltagi M, Serag AR, Hefidah MM, Mabrouk MM. Evaluation of cardiac functions with Doppler echocardiography in children with Down syndrome and anatomically normal heart. Cardiol Young. 2013;23(2):174-80. doi: 10.1017/S1047951112000613. [PubMed: 22717046].

22. Kimball KJ, Numnum TM, Kirby TO,Zamboni WC, Estes JM, Barnes MN, et al. A phase I study of lapatinib in combination with carboplatin 
in women with platinum sensitive recurrent ovarian carcinoma. Gynecol Oncol. 2008;111(1):95-101. doi: 10.1016/j.ygyno.2008.07.001. [PubMed: 18692224].

23. Pastore E, Marino B, Calzolari A, Digilio MC, Giannotti A, Turchetta A. Clinical and cardiorespiratory assessment in children with Down syndrome without congenital heart disease. Arch Pediatr Adolesc Med. 2000;154(4):408-10. [PubMed: 10768682].

24. Iellamo F, Galante A, Legramante JM, Lippi ME, Condoluci C, Albertini $\mathrm{G}$, et al. Altered autonomic cardiac regulation in individuals with Down syndrome. Am J Physiol Heart Circ Physiol. 2005;289(6):2387-91. doi:10.1152/ajpheart.00560.2005. [PubMed: 16024564].

25. Russo MG, Pacileo G, Marino B, Pisacane C, Calabro P, Ammirati A, et al. Echocardiographic evaluation of left ventricular systolic function in the Down syndrome. Am J Cardiol. 1998;81(10):1215-7. [PubMed: 9604950].

26. Fernhall B, Otterstetter M. Attenuated responses to sympathoexcitation in individuals with Down syndrome. J Appl Physiol (1985). 2003;94(6):2158-65. doi: 10.1152/japplphysiol.00959.2002. [PubMed: 12576412].

27. Goulopoulou S, Baynard T, Collier S, Giannopoulou I, Figueroa A, Beets M, et al. Cardiac autonomic control in individuals with Down syndrome. Am J Ment Retard. 2006;111(1):27-34. doi: 10.1352/08958017(2006)111[27:CACIIW]2.0.CO;2. [PubMed: 16332154].

28. Recalde AL, Landing BH, Lipsey AI. Increased cardiac muscle fiber size and reduced cell number in Down syndrome: heart muscle cell number in Down syndrome. Pediatr Pathol. 1986;6(1):47-53. [PubMed: 2950384].

29. Fuentes JJ, Genesca L, Kingsbury TJ, Cunningham KW, Perez-Riba M, Estivill X, et al. DSCR1, overexpressed in Down syndrome, is an inhibitor of calcineurin-mediated signaling pathways. Hum Mol Genet. 2000;9(11):1681-90. [PubMed: 10861295].

30. Tandan S, Wang Y, Wang TT, Jiang N, Hall DD, Hell JW, et al. Physical and functional interaction between calcineurin and the cardiac L-type Ca2+ channel. Circ Res. 2009;105(1):51-60. doi: 10.1161/CIRCRESAHA.109.199828. [PubMed: 19478199].

31. Sharma M, Khera S, Sondhi V, Devgan A. A study to determine the prevalence of pulmonary arterial hypertension in children with Down syndrome and congenital heart disease. Med J Armed Forces India. 2013;69(3):241-5. doi:10.1016/j.mjafi.2012.11.013. [PubMed 24600117].

32. Banjar HH. Causes of pulmonary hypertension among children. Curr Pediatr Res. 2013;17(1). 